\title{
"Education Abroad" for International Student Advisors: What Is the Impact on Their Professional Development?
}

\section{Wei Liu ${ }^{\mathrm{a}}$}

\begin{abstract}
It is generally agreed that participating in study abroad programs, even short term, has positive impacts on students. But what would be the impact of an "education abroad" opportunity for staff members in international education? Reported in this paper is a 3-month professional development program in a Canadian university for 52 international student advisors from 51 different Chinese institutions. Based on data from a survey and their comparative research reports, the study aims to glean the impacts of such an education abroad opportunity for international education professionals after their exposure to a different national context and different practices in international education. Findings of this study show that international comparison can serve as an effective approach to the professional development of international education professionals, which enhances their historical, contextual, and cultural understanding of their own work.
\end{abstract}

Keywords: China, Canada, education abroad, international student advisors, professional development

\section{Introduction}

In 2012, China became the world's third most popular study destination for international students, and the most popular in Asia (ICEF Monitor, 2017). In the People's Republic of China, the term "international students" refers to students studying in China who hold non-Chinese citizenships. However, Chinese citizens who immigrated from China (including Hong Kong, Macao, and Taiwan) are only considered foreign citizens when they have gained non-Chinese citizenship for up to 4 years and have lived overseas for the immediate past 2 years upon their application to Chinese universities (see Ministry of Education of the People's Republic of China [MoE], 2009). China currently does not recognize dual citizenships.

According to the Chinese MoE statistics in 2015, there are close to 400,000 international students studying in China's over 800 institutions (MoE, 2016), and this is about 100,000

a University of Alberta. 
short of the enrollment target of 500,000 by 2020 in the government's Study in China Plan (MoE, 2010). China also hopes to significantly improve the quality of international student education by 2020 , according to a policy paper of the State Council on the internationalization of Chinese education (State Council, 2016).

In student services, China has a national policy of one dedicated student advisor for each 200 undergraduate students (an earlier standard was 1 to 150; MoE 2006), working as a one-stop shop of services (Liu \& Lin, 2016). A recent central government regulation on international student recruitment and education requires that the same 1:200 ratio apply to the services of international students (MoE, 2017). What this means is that there should be a team of about 2,000 international student advisors in Chinese universities providing services to the 400,000 international students.

As an emerging destination country for international education, international student advising in China is a new and growing profession. Apart from the quality of academic programming, the competence of international student service providers and their ongoing professional development are important factors to international students' overall learning experience and success in China. Reported in this study is a professional development opportunity for 52 international student advisors from 51 Chinese institutions in a cross-national and cross-cultural context. The goal of this study is to explore the impact of this "study abroad" opportunity for the professional development of international student advisors.

\section{Study Abroad}

A global survey of the International Association of Universities shows that study abroad has great impact on the student self, including academic achievement, personal growth and independence, the ability to manage identity change, and a stronger sense of selfefficacy $(\mathrm{Gu}, 2012)$. Another survey study conducted by the Institute for the International Education of Students found that a study abroad experience is often seen as a defining moment of a young person's life, and the benefits of such an experience in one's personal growth, intercultural development, and education/career development last long after the experience itself (Dwyer, 2017). At the national level, students with study abroad experience may develop a sense of "enlightened nationalism" (C. Jones, 2015), when they become more aware of and more tolerant of the different values held by different countries, and less prone to seeing such differences as a source of threat to one's national security.

A NAFSA synthetic analysis of many existing studies measuring the impact of study abroad shows that international learning experiences have positive impacts on students' academic, educational, and professional outcomes, both in immediate and lifelong terms (NAFSA, 2017). Specifically, the benefits include:

- improves completion, retention, and transfer (to degree programs) rates;

- improves grade point average;

- improves language learning;

- fosters intercultural understanding, provides a global context, and builds enlightened nationalism; and

- increases employability and career skills. 
In sum, there seems to be convincing evidence to demonstrate the benefits of a study abroad opportunity to students as a learning activity. The most common goal for education abroad programs is to help students acquire intercultural competences so that they are able to fully participate in the international world (Stier, 2004). Education abroad experiences benefit university students in their development of cognitive, affective, and behavioral skills in cross-cultural communication so much so that it can be a transformative experience for some individuals (Root \& Ngampornchai, 2012). Being exposed to and having to adapt to an unfamiliar academic setting enriches the overall academic experiences of students. But what could be the impact of a study abroad opportunity on international education professionals? In particular, what would be the benefits for international student advisors to walk out of their own national environment and immediate work context and get exposed to a different national and cultural system of international education and student services?

\section{The Case Study}

Examined in this paper as a case study is a 3-month-long professional development program for 52 international student advisors from China in a study abroad context. The 52 international student advisors were selected from 51 different Chinese universities by the China Scholarship Council who also provided funding for the program. Over $80 \%$ of these 51 universities represented are strong national universities who receive central government funding. They are either Project 211 universities and/or Project 985 universities. Project 211 was initiated in 1995 to provide extra national funding to 100 or so select Chinese universities in order to raise their research standard for the 21st century; Project 985 was initiated in 1998 to provide even more national funding to top Chinese institutions (altogether 39 institutions funded) to allow them to compete with the firstclass universities in the world (see e.g., Zhang, Patton \& Kenney, 2013). The other $20 \%$ of the participants in the program were from key provincial universities. The program was hosted and delivered at a Canadian university in the summer of 2016. The university is one of the top five research-intensive universities in Canada with a strong international profile.

The 3-month curriculum aimed to expose the 52 Chinese colleagues to the practices in international education in the Canadian university in five modules. Module 1 introduces the university governance system in Canada, including the higher education system in Canada, the relationship between governments and universities, and the bicameral governance model within a university. Module 2 is on higher education internationalization strategies in Canada, both at the national level and institutional level. Module 3 is more specifically about the international student recruitment strategies and practices in the Canadian university. Module 4 is on international student services. And the last module is a series of supporting activities to help participants immerse in Canadian life and culture, including some site visits and 10 sessions of high-level contentbased ESL. Figure 1 summarizes the organization of the five modules:

The five modules were delivered in diverse forms, such as whole-class lectures, smaller scale round tables, and even smaller counterpart meetings. There were ongoing discussion sessions with facilitations by staff members at the Canadian university. The participants 


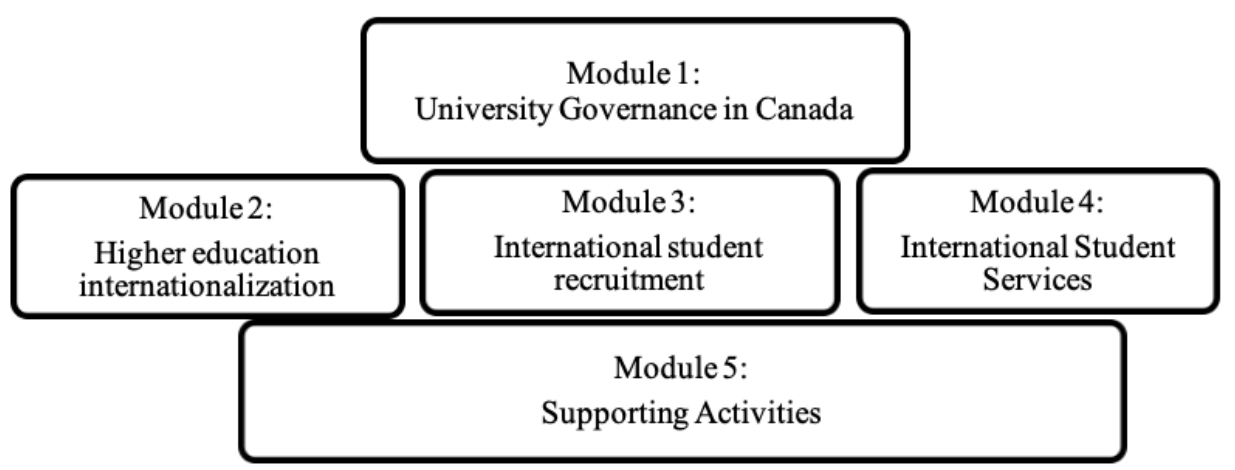

Figure 1. Organization of the five curriculum modules

were required by the funding agency to conduct rigorous comparative research on selfchosen topics, using information obtained from the program, and they were to hand in their research reports upon the end of the program. The 52 participants also conducted multiple surveys among themselves on different issues in order to compare and reference practices in international education in the 51 different universities in China. The results of these surveys are mentioned in their research reports.

Permission was obtained from the 52 Chinese colleagues to use their research reports (altogether 400 pages) as data to inform this study. An analysis of the 52 research reports shows that their research has focused on the following three major areas of Canadian practices in international education:

- Higher education internationalization strategies (19 reports), such as the Canadian international education strategy, the international education strategies at the Canadian university, and different international education programming;

- International student recruitment (13 reports), such as international student recruitment strategy and marketing and communications in international student recruitment;

- International student services (20 reports), such as the model of student services in Canada and the student-centered concept in student services.

Most reports start with factual accounts of the governance and administrative structure at the Canadian university, particularly the structure and practices of student services. Following the factual account is typically a comparison with the Chinese system, and based on the comparisons, the authors almost unanimously make policy recommendations at the end. In addition to their research reports, another source of data for this study is the program evaluation survey conducted at the end of the program. Apart from questions to elicit their feedback on the delivery of the program itself, there are three open-ended questions in the survey that aimed to collect data on their learning outcome during the program:

- When you return to your home institution, and your colleagues ask you about the differences in international education in Canada and China, what would you say? 
- Based on your understanding, what practices in international education at the Canadian university are worth borrowing by Chinese institutions?

- Based on your understanding, what practices in international education in Chinese universities should be borrowed by Canadian universities?

The third source of data was collected ethnographically through long-term engagement during the program by the researcher who also worked as the curriculum designer, program manager, and the learning facilitator. The researcher, with bilingual skills and cross-cultural research experience in China and Canada, participated in most wholegroup lectures, taking research journals on interactions between 52 Chinese colleagues and their Canadian counterparts. Research journals were also taken to record key points in the discussions within the group to compare the different practices.

According to Deardorff's (2006) pyramid model of international competence, the outcomes of international learning experiences can be measured by examining the acquired degree of knowledge/ comprehension, skills, desired internal and external outcome. Given the data available, we were not able to examine their more abstract skill development, nor their behavioural outcomes. Instead, the data analysis focused on their growth in cross-cultural knowledge and comprehension of their work. "Phenomenological themes may be understood as the structures of experience." (van Manen, 1990, p. 79) A thematic analysis was conducted on the information of the qualitative data with a balanced focus on frequency and saliency. Three themes emerged based on the frequency of their appearance, and the 4th theme was added based on its saliency and relevance to the issue of professional development.

\section{Findings}

In this section, the four themes derived from data analysis will be presented as findings of the study. These four themes serve to demonstrate the major impacts of this "study abroad" experience on the 52 international student advisors' professional learning.

\section{Raised historical awareness of higher education development in China}

The data first shows evidence that the Chinese group of advisors has developed a heightened awareness of the different historical contexts of the two higher education systems. The group learned that the Canadian university was established in 1908 in one of the prairie provinces in Canada. Coincidentally many top Chinese universities were established during the same period, such as Beijing University in 1898, Nankai University in 1904, and Tsinghua University in 1911 (based on their institutional websites). However, the Canadian university enjoyed relatively peaceful development and stable investment throughout the 20th century, as no war was fought on the mainland of Canada. But this was not the case for China.

In 1911, a republican revolution led by Sun Yet-Sun overturned the Qing Dynasty (1644-1912) and ended the feudalist rule in China. During the following 37 years of the Republican Government (1912-1949), the country experienced three civil wars (1924-1927; 1927-1937; 1945-1949) and the Second World War (WWII) in between (1931-1945) during which the Republican Army and the Communist Army joined hands 
to fight the Japanese invitation. In 1937, when the Japanese troops took over Beijing and Tianjin, Beijing University, Tsinghua University, and Nankai University had to move all the way to the southern border city of Kunming and merge into the Southwest United University (Yi, 2012).

After WWII, higher education in Canada enjoyed fast development and quick expansion due to the veterans' benefits program, which provided free university education for veterans returned from the wars overseas (G. A. Jones, 2014). However, after WWII, China experienced the Cultural Revolution (1966-1976) when universities were closed and scholars were considered dangerous people to the Communist cause (see e.g., Chan, 1985). The Chinese group of advisors believed that the real development of higher education in China has been since the 1980s. After the Cultural Revolution, the new Chinese leadership began to introduce market principle in running the economy. And in higher education, the government began to change the highly centralized system built in the 1950s and began to gradually shift more autonomy to individual universities (Mok, 1999). The government investment in higher education increased in large margins in the 1990s through the 211 and 985 projects, as we mentioned above.

As a result of the different historical paths, the Chinese group of advisors believed that Canada and China are at different stages of development in higher education. They were impressed by the buildings and facilities of the Canadian university, such as the 24-hour hot water supply and the same room temperature kept all year round, things taken for granted in Canada. They were impressed by the level of "Informationization" in the Canadian university, a Chinese term to refer to the use of information technology in teaching, research, administrative work, and student services. They liked the fully integrated online system for students' registration, course selection, research administration, and online course offering. They also liked the institution-wide uniform email system for faculty, staff, students, and visitors. As an example, one participant said the following:

The Chinese government has increased investment in higher education in the past four decades, and the Chinese higher education system has experienced fast development. However, compared with Canadian universities, we need still more investment so as to improve the general quality of Chinese higher education provision, both hardware wise and software wise.

They were most impressed by the high level of internationalization in Canada as a whole, with over $10 \%$ of undergraduate students being international and over $40 \%$ of faculties having at least one degree from overseas (see Canadian Bureau for International Education, 2018). They admired the large number of high quality student services provided at the Canadian university for both domestic and international students, which they believe truly reflect the principle of "student centeredness." They paid attention to the full credit system taken for granted in North American universities that gives students easy mobility between programs and institutions. But such freedom requires resources in terms of the large number of available courses and staff's time to process these transfers. The group found that the number of administrative staff is higher in Canada, with a rough 
ratio of about 2 to 1 with academic staff, while the ratio in Chinese universities is about 1 to 1 . One participant wrote in her report:

Professors from my university always say that we have too many administrative staff, often quoting that the overseas universities are more effective in their operations. But since coming here, I realized that Chinese universities have way fewer administrators in proportion! We would need to more people to provide more and better services.

\section{Raised contextual awareness of the policy framework for international education in China}

The data also show evidence that, through comparison, the group of advisors grew a heightened awareness of the national policy framework for international education in China. According to their observation, the Chinese government is the funder, manager, and evaluator of higher education in China, while in Canada, the governments are the principal funder of higher education, but universities have more autonomy in management and evaluation. In terms of international student education, Chinese universities receive strong financial support from Chinese governments to grow international student recruitment. According to Chinese MoE data (2016), there were 40,600 international students supported by Chinese government scholarships in 2015 , which was about $10.21 \%$ of all international students studying in China. Of the 40,600 government scholarship students, about $68 \%$ were graduate degree students, $22 \%$ undergraduate degree students, and 10\% non-degree students (e.g. language and cultural studies). The group learned that there are scholarships in Canada for international graduate students (mostly funded by professors' research dollars), but very few and very little for international undergraduate students and non-degree students.

But the more centralized higher education management and evaluation system in China also sets limitations for institutions' internationalization effort. One participant wrote in her report,

The university in China is taken, not as an independent legal entity, but as an administrative unit of the government with the President appointed as a civil servant and a government official. Thus, the university lacks autonomy in institutional decision making, including policies in internationalization.

One example given by the Chinese group of advisors is international dual degree programs. The degrees offered in China are theoretically all offered by the national government, as the government has the ownership and oversight of all degrees offered by Chinese institutions. Thus, when Chinese universities hope to start a dual degree program with an overseas partner or to deliver their programs overseas, it will have to be approved by the government. They learned that in Canada, universities have ownership of their degrees and thus have freedom to engage in international dual degree collaboration and oversea deliveries, as far as they are existing programs. 
China also has a planned quota system for all government employees, including employees in universities (faculty and staff). Universities have to hire within the number allocated by the government. The group reported that their offices are often short-staffed with the quick increase of international students and the national quota system does not allow them to freely increase staff members, even if they have the budget. They will have to apply to the central Human Resources office for new positions due to the quota system. One of the surveys among the 51 Chinese institutions suggests that most universities (about 70\%) have only six to eight staff members in their Faculty of International Education where all their international students are housed; $64 \%$ of the universities have only one to two dedicated staff members for international recruitment. Only $10 \%$ of these have over six staff members for recruitment. Given this reason, most of them have multiple roles to play, such as marketing and recruitment, agent relations, daily advising, and relations and communications with teaching colleges/departments. The recent national government regulation on one dedicated advisor for each 200 international students might be able to change this situation (MoE, 2017). According to one participant:

As we are short-staffed, it is quite common for us to work overtime. We feel jealous to learn that the international office at the Canadian university has freedom to add staff members when necessary and our Canadian counterparts do not have to work overtime as often as we do.

The group realizes that, as Canada is an immigration country, it welcomes international graduates to stay to work after graduation. For this reason, many staff members at the International Office of the Canadian university have experiences in international education themselves, and many were international students to Canada who stayed on to work. In contrast, most staff members working in international education in China have a more uniform background, typically with a degree in foreign language studies from Chinese institutions. They would love to hire people who have international backgrounds to work in different regions of their expertise, but for a long time, the Chinese government did not allow their international students to stay and work in China upon graduation. A recent policy from the national government has allowed a limited number of international students (who graduated with master's degrees and above) to stay and work in China. This might change the situation and help increase the professional level of their staff.

International travel policy of government officials, including mid-level and senior administrators at universities, is another limitation on their internationalization effort. According to the current policy, mid-level and senior administrators (Associate Deans/Associate Directors and above) must hand in their passports to the university to keep. Their international travel plans must be approved through an internal procedure within the university, and then approved by the governments, before they can obtain their passports and apply for overseas visas. In general, each academic college/department's annual international travel plans must be included in the institutional annual plan before their trips are to be approved. And in principle, an international delegation sent by an academic unit must not have over three delegates. In addition, they can only spend up to 5 days in one country, no more than 8 days in two countries during one trip. The national policy is part of the national anti-corruption campaign, but it can cause many 
inconveniences to universities' internationalization missions. One participant mentioned the following in a discussion session:

When our senior university administrators need to travel overseas, it is a common practice to book the flights to leave China after midnight so that we can spend more time for activities but still meet the requirement of no more than 5 days in one country.

The group of advisors considered themselves very lucky to be selected to attend this 3month program overseas. As the program is organized by the national government as a professional training opportunity, it can bypass the 5-day-in-one-country policy for international business trips.

\section{Raised cross-cultural awareness of student development in China}

The data also show evidence that the group of advisors increased their cross-cultural understanding of student development in the two countries, and the two student development cultures are related to the demographic contexts of the two countries. The two countries have similar land sizes, but very different populations: for each Canadian, there are 40 Chinese! Given a smaller population, the group learned that Canada's participation rates in higher education are among the highest in the world (see e.g.,G. Jones, 2014). Canada ranks first among the Organisation for Economic Cooperation and Development countries in the proportion of adults with a college education (24\%) and ranks eighth in the proportion of adults with a university education (26\%) (Organisation for Economic Cooperation and Development, 2012). Though China quickly expanded undergraduate enrollment around the turn of the century, the demand for higher education is still very high. In particular, China has an education-first culture (see Liu, 2016), as a result of which all parents want their children to go to top-ranked universities.

Through comparison, the Chinese group believe that Chinese higher education can be said to be a "seller's market" as the demand is much higher than supply, while compared to China, Canada's higher education is almost a "buyer's market," since the entrance to postsecondary education is not as competitive and students have many more options. University entrance in Canada is based on students' applications with high school grades, while in China, to ensure fairness in a competitive environment, university admission is based on a national exam as a uniform selection tool, known as Gao Kao. According to the reflection of the Chinese group, Gao Kao in a way creates different expectations in Chinese students and parents out of university education. One participant commented,

Once students pass Gao Kao and get admitted into a university, it means that they have demonstrated ability to succeed in higher education. It is thus the university's failure if they do not graduate.

The Chinese group were shocked to learn that $20 \%$ of Canadian students on average fail to graduate from their universities within 6 years (see Jeong, 2016), as in China, every university aims for $100 \%$ graduation rate within 4 years. For every course, there are makeup exams if students fail at the first attempt. If they fail at the second attempt, they can take 
part in a final make-up exam before graduation. Students in Chinese universities pay a set amount of tuition by the year, and they can take as many courses as they can within the year. If students are not happy with the mark of a course, they can take the course multiple times without paying additional fees, and the highest appears on their transcripts. One participant joked,

If $20 \%$ of our undergrads fail to graduate, we will be in trouble, and our president will be in trouble too. Satisfactory graduation rate is used as an important measure of the quality of education by the governments.

The Chinese group believe that the Canadian university takes "limited" responsibility for students' success, while universities in China take "unlimited" responsibility for students. One participant of the group shared that, in her university's international preparatory program funded by the Chinese government to prepare government scholarship winners for degree studies, one dedicated staff member is arranged to go to the classroom to take attendance every morning. For students who are late for class, he or she will warn them in person; for students who skip $10 \%$ of the classes, the university will report them to the funding agency in the central Chinese government; for students who skip $20 \%$ of the classes, the university will report to the funding agency and notify the embassy of the students' governments; for students who skip $30 \%$ of the classes, the university would expel them, and report to the funding agency to cancel the scholarship, copying the students' embassy as well. For students who never skip a single class, the university would give out certificates of full attendance as recognition and encouragement. They learned that, in Canada, the professors and administrators typically do not take students' attendance in class, as they do not see it as their duty to make sure they come to class.

Some members of the Chinese group shared that one of the most difficult moments for Chinese university administrators is when a student dies accidentally or commits suicide on campus, which unfortunately happens both in China and Canada. In the Chinese case, the parents would always hold the university accountable for their child's death, as they died under the university's care. Economic compensation is often made to their parents by the university to settle the issue. The Chinese colleagues asked their Canadian counterparts if they had to deal with the same issue. The answer is no, as the students are adults and they are responsible for what they are doing. They learned that young people in Canada are considered "adults" as soon as they turn 18, and they need to take full responsibility for their life and study, while in China, university students are still considered "adults in training" (see Liu \& Lin, 2016).

Given the different understanding of university student development, this group of advisors feel that the goal of student affairs work in China is more concerned about controlling potential risks for students and keeping them free from troubles. To ensure the safety of students in China, one universal practice, for example, is to require all students to stay in residence on campus, and there is a curfew in place requiring students to return to their dorm room before a certain time at night. In addition, students are not allowed visitors in their dorms. There are guards stationed at the entrance of each residence to enforce the curfew and no-visitor rule. The same practice is implemented for international students. First, international students are typically housed in separate accommodations 
from domestic Chinese students. One piece of Chinese legislation for foreign nationals is that they are supposed to report their residences to the local Chinese police departments within a short time upon their arrival in China, and there are designated accommodations for foreign nationals, which do not include Chinese student dorms. But similar to the rules for Chinese students, there is a curfew in the international residences and students are not allowed visitors in their dorms overnight. However, according to the Chinese advisors,

Such rules have caused much dissatisfaction among international students and they are often perceived as intrusions into international students' personal freedom.

\section{Formation of a professional learning community for international education in China}

Though members of the group have been working in the same field in China in different universities, not many of them knew each other personally before they came to study in this program. During the 3 months in the program, the 52 Chinese colleagues seemed to have formed a strong and tight "community of practice" (Wenger, 1998) in international student services. One participant has commented,

We enjoy being part of a professional learning community for sharing and mutual learning of practices in diverse universities in China.

We have mentioned above that the group took the opportunity to talk and survey among themselves for the purposes of comparing and referencing policies in different institutions. For example, through an internal information gathering survey, they learned that 38 of the 51 universities are using a separate international student information management system from domestic students, while eight universities use the same system for both domestic and international students, and another five don't have a system yet. They also shared information about which commercial systems they are using and which one is rated the highest. During the program, they all formed a Wechat (a popular cellphone social media app) group, and the Wechat group has kept the professional learning community going after they returned to China. Being a member of the group, the author could observe that the group members asked each other questions about practices in other institutions on different issues constantly. They also visit each other's universities when they identify the best practices among themselves.

\section{Discussion}

Given the advances of globalization, education systems are no longer defined on a national basis only (Crossley, 2002; Crossley \& Broadfoot 1992). In the 21st century, comparative education has been increasingly used as international benchmarks to evaluate educational quality and efficiency at home (see e.g., Green 2003; Lang \& Zha 2004; Nóvoa \& YaruvMarshal, 2003). In this sense, it is important to create opportunities for administrators in higher education to be exposed to other systems so that they can reference practices elsewhere as benchmarks. However, it is a complex task to assess the extent to which 
a desirable policy observed elsewhere can be adopted and adapted to fit the home circumstances and thus become part of the home system (Phillips \& Ochs, 2004). To know what is transferrable and what is not, a deep and systematic analysis through comparative research is needed to reveal the historical, cultural, and economic contexts of different practices.

However, policy borrowing does not have to be the most important goal in international benchmarking. Through comparisons with the Canadian system, the group in this study seem to have obtained a deeper understanding of their own work at home, and this can be said to be a more important impact of this study abroad experience on the participants. The data shows evidence of their raised historical awareness of higher education development in China, raised contextual awareness of policy framework for international education in China, and raised cross-cultural awareness of student development in China. In addition, we are glad to see the formation of a professional learning community for international education for China that can sustain their learning in years to come.

In teacher education research, scholars have shown the importance of a bottom-up approach in teachers' professional development (see e.g., Connelly \& Clandinin, 1988; Lieberman \& Wood, 2003; Whitehead \& McNiff, 2006). The bottom-up approach speaks to the importance of communicating with colleagues in the same profession in a more casual and friendly fashion, as was discussed above. It also speaks to the importance of learning from lived experiences on the ground. One Chinese colleague in the program commented, "We benefited from the lived experience as an 'international student' studying abroad so that we can understand the needs of our international students going to study in China." Another participant shared his observation of the humanistic and caring culture in Canada beyond the university campus: kneeling buses to provide accessibility of public facilities to the disabled; people talking more quietly in public; holding doors for people coming behind; saying hi to strangers; standing to the right on escalators; saying thanks to bus drivers; and saying "sorry" all the time. Such observations from lived experience in a foreign study abroad context are qualitatively superior to reading them from the books.

International comparison can be an effective approach to the professional development of international education professionals, particularly for those with no or limited prior international learning experience. Such a study abroad opportunity has provided the Chinese group in this study a global perspective on what they do in China. The experience has provided assurance and confirmation of some of their practices in China, such as the proactive model in student services (see Liu \& Lin, 2016). The experience has also challenged them to reconsider some of the practices they have taken as natural in China, such as the differential model in international student management (also see Liu \& Lin, 2016). The impact of international comparison as an approach to professional development should not be measured by what participants can borrow from another system, but by how much more they can understand their own work as a result of this experience. Observed differences built in deep historical, contextual, and cultural understanding can serve as a good foundation for innovation in future practices.

\section{Conclusion}


Similar to the previous research findings with regard to the impacts of study abroad experiences for students, a study abroad opportunity can also have very positive impact on the professional development of international student advisors in deepening their understanding of their own work, and such deeper understanding can serve as foundations of their innovation in their future practices. To strengthen the impact and avoid simplistic understanding, engaging them in comparative analysis, applied research, and enriched local experience can be important tools when implementing such a program.

\section{References}

Chan, A. (1985). Children of Mao: Personality development and political activism in the Red Guard generation. University of Washington Press, Seattle.

Connelly, F. M. \& Clandinin, D. J. (1988). Teachers as curriculum planners: Narratives of experience. Teachers College Press, New York.

Crossley, M. (2002). Comparative and international education: Contemporary challenges, reconceptualization and new directions for the field. Current Issues in Comparative Education, 4(2), 81-86.

Crossley, M. \& Broadfoot, P. (1992). Comparative and international research in education: Scope, problems and potential. British Educational Research Journal, 18(2), 99-112.

Deardorff, D. K. (2006). Identification and assessment of intercultural competence as a student outcome of internationalization. Journal of Studies in International Education, 10(3), 241-266.

Dwyer, M. (2017). 27.). The benefits of study abroad.

Green, A. (2003). Education, globalization and the role of comparative research. London Review of Education, 1(2), 83-97.

$\mathrm{Gu}, \mathrm{Q}$. (2012). The impact of study abroad on the student self. University World.

Jeong, J. (2016). 16). The big data revolution: Will it help university students graduate? The Globe and Mail.

Jones, C. (2015). 10). The surprising effects of study abroad. Washington.

Jones, G. A. (2014). An introduction to higher education in Canada. In Joshi, K. M. \& Paivandi, S., editors, Higher education across nations, volume 1, pages 1-38, Delhi: B. R. Publishing.

Lang, D. W. \& Zha, Q. (2004). Comparing universities: A case study between Canada and China. Higher Education Policy, 17, 339-354.

Lieberman, A. \& Wood, D. (2003). Inside the National Writing Project: Connecting network learning and classroom teaching. Teachers College Press, New York.

Liu, W. (2016). The international mobility of Chinese students: A cultural perspective. Canadian Journal of Higher Education, 46(4), 41-59.

Liu, W. \& Lin, X. (2016). Meeting the needs of Chinese international Students: Is there anything we can learn from their home system? Journal of Studies in International Education, 20(4), 357-370.

Manen, M. (1990). Researching lived experience: Human science for an action sensitive pedagogy. The Althouse Press, London. 
Mok, K. H. (1999). Education and the market place in Hong Kong and mainland China. Higher Education, 37(2), 133-158.

Monitor, I. C. E. F. (2017). China now the world's third most-popular study destination.

Nóvoa, A. \& Yaruv-Mashal, T. (2003). Comparative research in education: A mode of governance or a historical journey? Comparative Education, 39(4), 423-438.

Phillips, D. \& Ochs, K. (2004). Researching policy borrowing: Some methodological challenges in comparative education. British Educational Research Journal, 30(6), 773784.

Root, E. \& Ngampornchai, A. (2012). "I came back as a new human being": Students descriptions of intercultural descriptions of intercultural competence acquired through education abroad experiences. Journal of Studies in International Education, 17(5), 513532.

Stier, J. (2004). Taking a critical stance toward internationalization ideologies in higher education: Idealism, instrumentalism and educationalism. Globalisation, Societies and Education, 2(1), 1-28.

Wenger, E. (1998). Communities of practice: Learning, meaning, and identity. Cambridge University Press, Cambridge.

Whitehead, J. \& McNiff, J. (2006). Action research living theory. = Thousand Oaks. Sage, CA. Yi, S. (2012). Southwest United University in war and revolution [Chinese]. Jiuzhou Press, Beijing.

Zhang, H., Patton, D., \& Kenney, M. (2013). Building global-class universities: Assessing the impact of the 985 Project. Research Policy, 42(3), 765-775.

\section{Author biography}

Wei Liu obtained his PhD in Education from Beijing Normal University, and he was the Myer Horowitz Postdoctoral Fellow (2011-2012) in Teacher Education and Professional Development at the University of Alberta. Currently he is working at the University of Alberta International, managing the Global Academic Leadership Development (GALD) Program, a professional development program for university administrators from a cross-cultural perspective. His research interests are in foreign language education and international education, and his recent publications have appeared in English Teaching: Practice and Critique, Educational Action Research, Journal of Studies in International Education, Canadian Journal of Higher Education, and Language Policy. 